\title{
Les péripéties d'une recherche : l'étude de la différenciation sexuelle
}

\section{Alfred Jost \\ 27 juillet 1916 \\ 3 février 1991}

Professeur honoraire au Collège de France. Secrétaire perpćtuel de l'Acadćmie des Sciences.
L'élucidation des mécanismes de la différenciation sexuelle est une prodigieuse aventure qui s'étend sur près d'un siècle. De la reconnaissance du rôle des sécrétions testiculaires dans le développement mâle à l'identification, aujourd'hui très probable, du gène localisé sur le chromosome $Y$ responsable de la différenciation testiculaire, et donc masculine, cette histoire possède son lot de passions, d'efforts, d'hommes et de femmes remarquables, de retournements de situation et de triomphes, tout ce qui est nécessaire à la constitution des épopées. C'est l'un des témoins et des acteurs principaux de cette épopée qui s'en fait l'historien et le mémorialiste. L'importance de sa contribution personnelle à la révélation des phénomènes en cause font de la revue du professeur Alfred Jost un magnifique article scientifique aussi bien qu'une passionnante et vivante relation d'une belle page de la progression des connaissances en biologie. Ce texte, très probablement le dernier de cette importance qu'ait écrit le professeur Jost, va même au-delà de la présentation d'un moment de l'histoire des sciences; il contient aussi un ultime message rejoignant les conclusions que le professeur Henri Géry Hers proposait dans le numéro de février 1991 de $\mathrm{m} / \mathrm{s}$ : "La liberté laissée à l'initiative des chercheurs fait davantage pour le progrès de la science que ne pourrait le faire quelque planification que ce soit". 


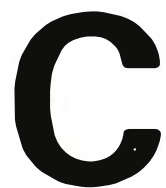

ette revue aurait pu s'intituler "Fille ou garçon ". J'ai renoncé à ce titre pour écarter de mon propos les méthodes de sélection qui pourraient répondre à ce choix, qu'il s'agisse de la sélection des spermatozoïdes porteurs du chromosome $\mathrm{Y}$, et seuls capables d'engendrer des garçons, ou de la sélection in vitro des embryons, en ne gardant que ceux du sexe désiré, identifié par les chromosomes XX pour les filles et XY pour les garçons.

Étudier la différenciation sexuelle c'est tenter de comprendre pourquoi et comment, à partir de sa conception, le germe deviendra un nouveauné masculin ou féminin, pourquoi également ce mécanisme a parfois des ratés.

Bien des réponses à ces questions ont été imaginées depuis l'Antiquité. L'étude scientifique a débuté au XIX siècle, d'abord descriptive avant de devenir expérimentale, pour aboutir au point de vue actuel. J'ai l'intention de retracer à grands traits le cheminement de cette recherche avec ses péripétics.

\section{L'apport du XIXe siècle : les données embryologiques de base}

Les embryologistes perspicaces du XIXe siècle ont jeté les fondements de nos connaissances, malgré des techniques encore peu performantes. Ils constataient tout d'abord que, chez l'embryon, les organes sexuels apparaissent simultanément dans les deux sexes et restent identiques jusqu'à un certain stade, stade dit indifférencié et qui est fugace. Les fœtus mâles vont soudain devenir reconnaissables, avant que les femelles n'acquièrent leurs caractéristiques.

L'appareil génital indifférencié comporte trois sortes de structures:

d'abord, les futures glandes génitales, ovaires ou testicules, ce qu'on appelle les gonades, situées haut dans l'abdomen chez le fotus ;

puis, sous les gonades, deux paires de canaux dont l'une servira chez les mâles (canaux de Wolff), et dont l'autre formera l'utérus et ses trompes chez les femelles. Les canaux à vocation féminine portent le nom de
- enfin un sinus uro-génital qui débouche sous un tubercule génital. Chacune de ces structures subira, pendant la différenciation des sexes, des changements divergents et complexes, qui ont été décrits en détail. Le $\mathrm{XX}$ e siècle, héritier de ces données, a cherché à élucider les mécanismes contrôlant l'émergence des deux sexes à partir du stade indifférencié.

\section{La théorie hormonale de la différenciation sexuelle}

L'histoire débute en 1903, avec deux pionniers de la biologie de la reproduction, Pol Bouin et Paul Ancel, qui étudiaient, à Nancy, la production de la " sécrétion interne " du testicule, sécrétion qui contrôle les caractères sexuels du mâle adulte. Le mot " hormone " n'avait pas encore été créé.

Bouin et Ancel venaient d'identifier les cellules glandulaires qui produisent cette sécrétion, les cellules interstitielles. Ils trouvent des cellules semblables dans les testicules des fœtus de porc à l'époque où leur appareil génital va être masculinisé, et en déduisent l'hypothèse que la sécrétion interne du testicule foetal "imprime à l'organisme, dès le principe, son cachet caractéristique (...) que ne pourra plus faire disparaître la castration même pratiquée dès la naissance " [1]. Cette première expression d'une théorie hormonale de la différenciation du sexe n'eut pas de suite immédiate.

Comme c'est souvent le cas en biologie ou en médecine, c'est à partir de l'observation d'un cas anormal que se comprend le fonctionnement normal. Ainsi la théorie hormonale de la différenciation du sexe devait renaître de l'examen d'une anomalie assez commune chez la vache, et qui frappe les femelles nées d'une grossesse gémellaire avec un jumeau mâle. Ces femelles vont devenir stériles et manifester parfois des propensions masculines. Dans nos campagnes, on les appelle souvent des mules. Dans les pays anglo-saxons, on utilise le terme ancien de freemartins dont l'étymologie est incertaine, mais qui s'est imposé en biologie. Les ovaires des freemartins sont très petits, atrophiés, parfois particllement masculinisés, les cornes utérines sont plus ou moins inhibées ou absentes. $\mathrm{Au}$ contraire certains organes masculins, les vésicules séminales, par exemple, se sont développés.

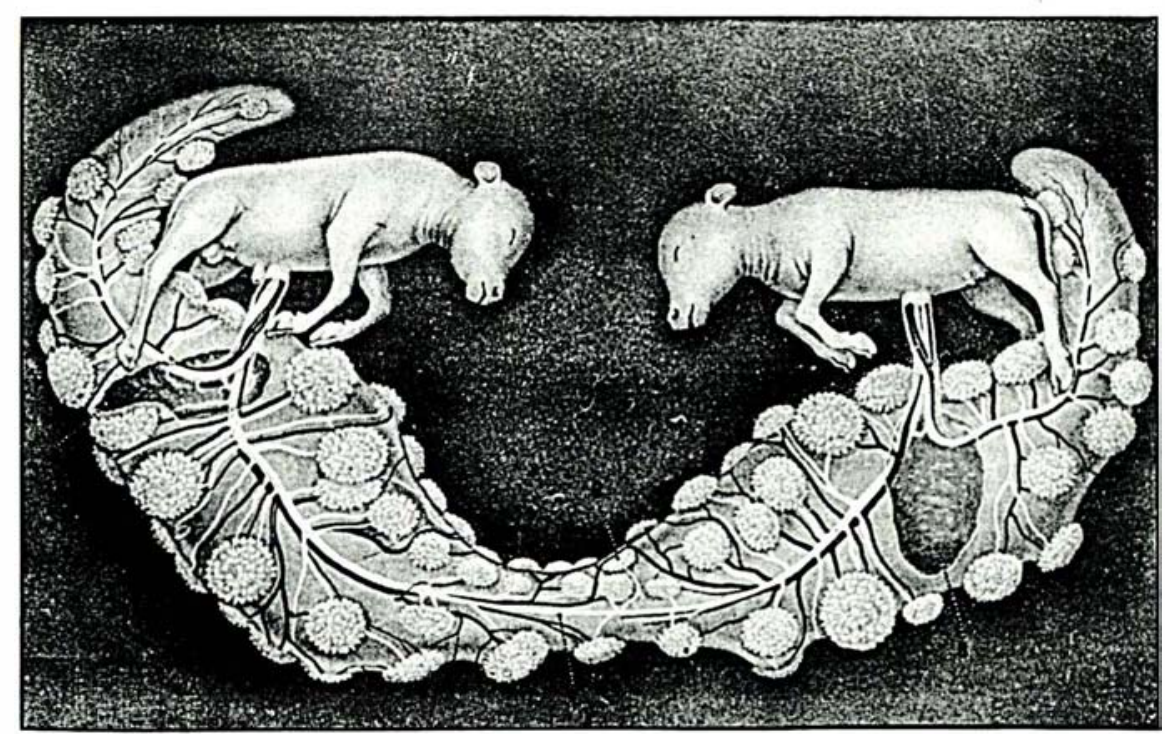

Figure 1. Figure classique de F. Lillie illustrant les anastomoses vasculaires chorioniques unissant deux veaux jumeaux. Ici sur un mâle là gauche) et une femelle (à droite). (D'après F. Lillie, J Exp Zool 1917; 23 : 371-452.) 


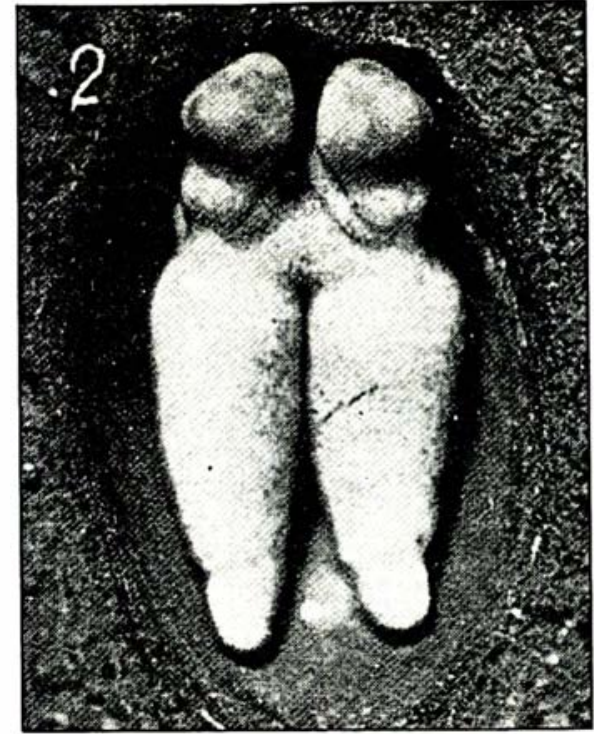

Figure 2. Réalisation de la parabiose chez l'ambystome. On voit une paire d'embryons soudés, cinq heures après l'opération, dans une petite cupule de cire. (D'après $R$. K. Burns, J Exp Zool 1930; 55 : 123-69.)

Or, dans les grossesses gémellaires de la vache, les chorions, ces poches dans lesquelles flottent les fœtus, fusionnent et lcurs vaisscaux s'anastomosent, ce qui entraîne l'échange des sangs entre les jumcaux (figure 1). A partir de ces obscrvations, Frank Lillic, professcur de zoologie à l'université de Chicago, proposc, en 1916, dans unc courte note, une théoric hormonale du freemartin [2]. Il suggère que les anomalics du freemartin sont dues à l'action sur la femelle présomptive de l'hormone testiculairc du jumeau mâle transmise par lcs anastomoses vasculaires.

La même année, en Autriche, Karl Keller et Julius Tandler, après une étude très détailléc, arrivaient à la même conception [3], mais ils furent moins écoutés que Lillie dont les élèves avaicnt poursuivi l'œuvre. La théorie hormonale fut partout attribuée à Lillie et acceptéc par tous. L'idéc de vérifier la théorie hormonale du freemartin hantait les esprits. Ellc fut rapidement illustréc par unc magnifique série d'cxpéricnces réalisées sur des batraciens.

En 1925, Robert Burns [4] rapporta des travaux qu'il avait cntrepris à l'université Yalc, dès 1922, c'est-àdirc six ans après la premièrc publi$\mathrm{m} / \mathrm{s} n^{\circ} 3$, vol. 7 , mars 91 cation de Lillic. Il opérait sur des larves encore immobiles d'un batracien, d'une salamandre américaine, l'ambystome. Il en accolait deux au nivcau d'une plaic supcrficiclle faite à chacunc d'elles. Au bout de quclques heures de cicatrisation, les larves étaient soudécs l'unc à l'autrc comme des frères siamois ct pour la vic (figures 2 et 3). Cettc parabiose permet l'échange des sangs avant la différenciation scxuelle.

Emil Witschi, un jeune biologistc suissc fixé aux États-Unis, utilisa la même technique pendant que Rufus Humphrey [5], de Buffalo, la modifiait, en échangeant, par la greffe, une même partic du corps entre deux larves (figures 4 et 5). Celles-ci étaient alors pourvues de deux gonades provenant d'individus différents.

Pendant près de vingt ans, ces trois chercheurs publièrent des analyses minuticuses de l'" effet freemartin", comme on disait, chez divers batraciens, et dans diverses conditions [6]. Les larves étaient prises au hasard. Il y avait donc $50 \%$ de chances pour que les deux partenaires soudés en parabiose soient de sexe différent. Dans ce cas, les ovaires des femelles, d'abord inhibés, étaient plus ou moins masculinisés comme chez les freemartins bovins.

Humphrey obtint les résultats les plus spectaculaires et les plus importants sur lc plan théorique. Il fut en effet lc premier à obtenir une réelle inversion du sexc : des femelles génétiques masculinisécs étaicnt devenues capables de se comporter comme des mâles et de féconder des femelles normales. L'étude de la descendance de l'union de ces deux femelles apportait, en 1945, la première preuve expérimentalc du contrôle génétique du sexe chez un vertébré [7]. En croisant entre elles deux femelles, l'une normale et l'autre masculiniséc phénotypiquement,

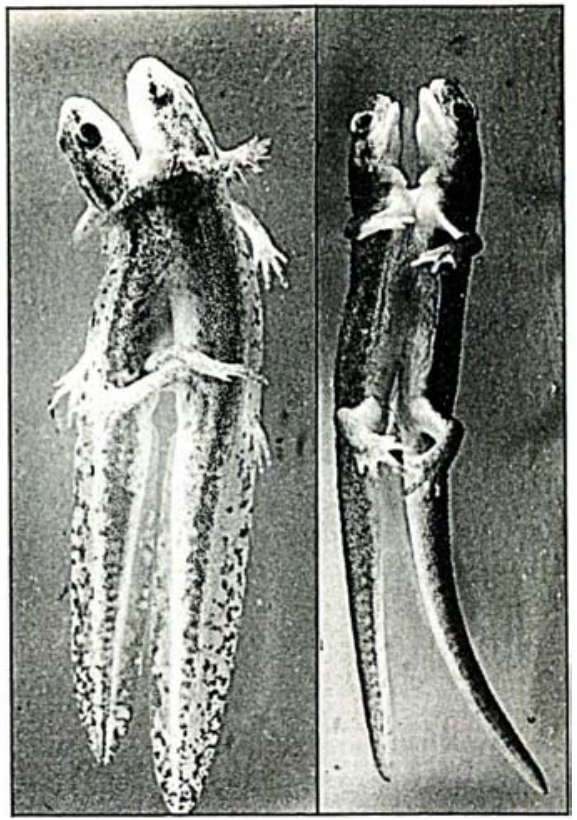

Figure 3. Parabiontes de tritons (Triturus torosus) adultes. Obtenus selon une technique semblable à celle de la figure 2. (D'après E. Witschi [50].)

Humphrey obtint dans la descendance trois femclles pour un mâle. Cela se comprend facilement si l'on admet que dans l'cspèce étudiéc, l'axolotl (Ambystoma mexicanum), c'cst lc sexc féminin qui possèdc deux chromosomes sexuels différents (dans cc cas, on les appelle ZW ct non XY commc chez les mammifères); lc sexc masculin, lui, possèdc dcux chromosomes semblables (appelés $\mathrm{ZZ}$ et non $\mathrm{XX}$ ).

Les femelles ZW produisent deux sortes de gamètes contenant soit le chromosome $\mathrm{Z}$ soit le $\mathrm{W}$ (on les dit hétérogamétiques). Les mâles sont homogamétiques, leurs gamètes portent tous le chromosome Z. Dans le croiscment, la répartition des chromosomes scxuels est la suivante (encadré ci-dessous).

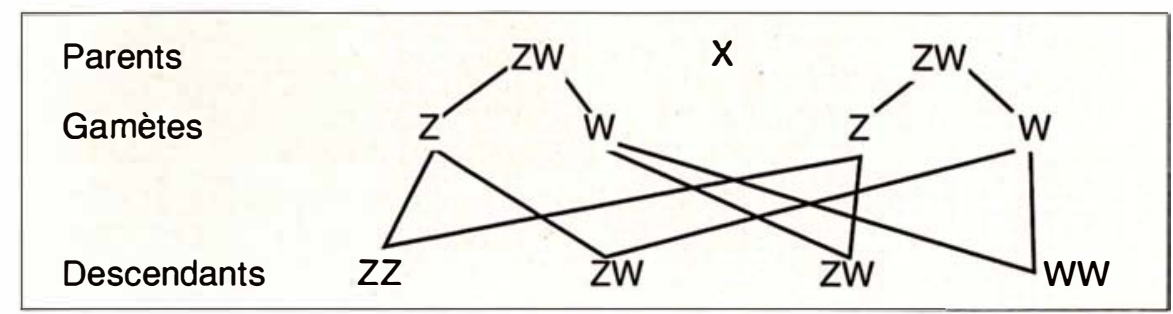




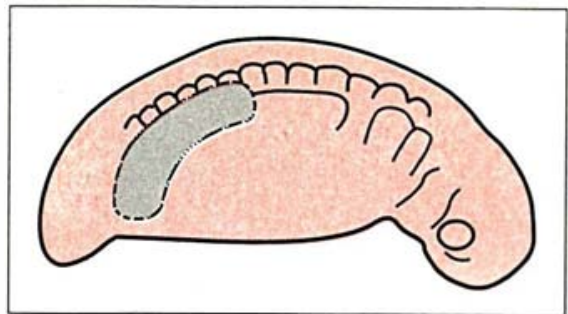

Figure 4. Technique de greffe orthotopique de Humphrey. Schéma d'une larve d'Ambystoma au stade 29 montrant en pointillé la région lectoderme + mésodermel enlevée et remplacée par une zone équivalente prise sur une autre larve. (Emprunté à Humphrey [5].)

La descendance comportc $25 \%$ d'animaux mâles $Z Z, 50 \%$ dc femclles ZW et $25 \%$ de femelles WW qui n'existent pas dans la nature. Si l'on croise ces femelles WW avec des mâles normaux $\mathrm{ZZ}$, la descendance doit être composéc de $100 \%$ de femelles ZW, ce que vérifia Humphrey.

\section{Les hormones sexuelles de l'adulte}

Mais entrc-temps, ailleurs, on isolait et on purifiait les hormones sexuelles de l'adulte. La première hormone ovarienne fut disponible pour l'expérimentation en 1934. Immédiatcment, plusieurs chercheurs tentèrent de vérifier la théorie hormonale de la différenciation du sexe en administrant l'hormone à l'cmbryon.

On débuta par l'embryon de poulet, plus accessible dans son œuf quc l'embryon intra-utérin des mammifères. En 1935, presque simultanément, Vera Dantchakoff [8], de Kaunas en Lituanie, Etienne Wolff [9] à Strasbourg, Benjamin Willier [10] à Baltimore injectent de l'hormone femclle à des embryons de poulct ct observent des modifications importantes de l'appareil génital des mâles. D'emblée les interprétations divergent. Vera Dantchakoff, unc petitc femme enthousiaste et impétueusc, écrit qu'elle a inversé le scxe des embryons. Wolff et Ginglinger sont plus précis, ils ont réalisé l'inter- c'est-à-dire un état où caractéristiques mâles et femelles sont mêlées.

L'expérimentation s'accélère alors. On dispose aussi d'hormones mâles, ce qu'on appelle les androgènes, et, à partir de 1936, on va faire agir les hormones sexuelles sur l'embryon des mammifères, des batraciens, des poissons ct des reptiles. Un nombre énorme dc publications va paraître pendant les trente années suivantes [6].

Dès 1936, Vera Dantchakoff publie, à Paris, trois mémoires sous le titre conquérant : "Réalisation du sexe à volonté par inductions hormonales " [11]. En fait, le problème n'était pas résolu. Le plus souvent, on réalisait l'intersexualité des embryons, en particulier chez les mammiferes [12].

Parfois, les hormones femelles masculinisent les femelles et les hormones mâles féminisent les mâles. On parle alors d'" effet paradoxal " [13]. Une vraic inversion fonctionnclle du sexe des gonades a cependant été obtenue dans un petit nombre de vertébrés inféricurs, batraciens ou poissons, dans des cas où l'hormone du sexc hétérogamétique XY ou ZW agit sur l'cmbryon homogamétique $\mathrm{XX}$ ou ZZ. Ainsi les cmbryons mâles ZZ de pleurodèle [14] ou de Xenopus [15] peuvent ĉtre féminisés sous l'action de l'œstradiol et se reproduire en s'accouplant avec des mâles normaux ZZ. La descendance de deux animaux $\mathrm{ZZ}$ comporte donc $100 \%$ de mâles $Z Z$, ce qui confirme les résultats de Humphrey cités plus haut.

Chez les mammifères placentaires, les hormones sexuelles ne modifient pas le sexe des gonades et ne reproduisent pas l'effet freemartin, même chez la vache. L'hormone fœtale responsable du freemartin n'est donc pas identique à l'hormone adulte [16].

\section{La castration du fœtus et les débuts de l'endocrinologie fotale}

Or à Chicago, Carl Moore, un élève de Frank Lillie devenu un endocrinologiste célèbre pour ses découvertes sur l'animal adulte, essaie de vérifier la théorie hormonale du freemartin en étudiant l'opossum, un marsupial des États-Unis. En 1939, il administre des hormones sexuelles aux petits encore fixés aux mamclons dans la poche marsupiale. Devant les effets paradoxaux obtenus, il commence à douter de la théoric hormonale de son maître Frank Lillic [17]. Pour mettre cette théoric à l'épreuve, en 1943, il castre chirurgicalement des jeunes opossums, dans la poche marsupiale, et supprime ainsi les hormoncs produites par leurs gonades [18]. Malgré la castration, l'utérus des femelles continuait à se dif-

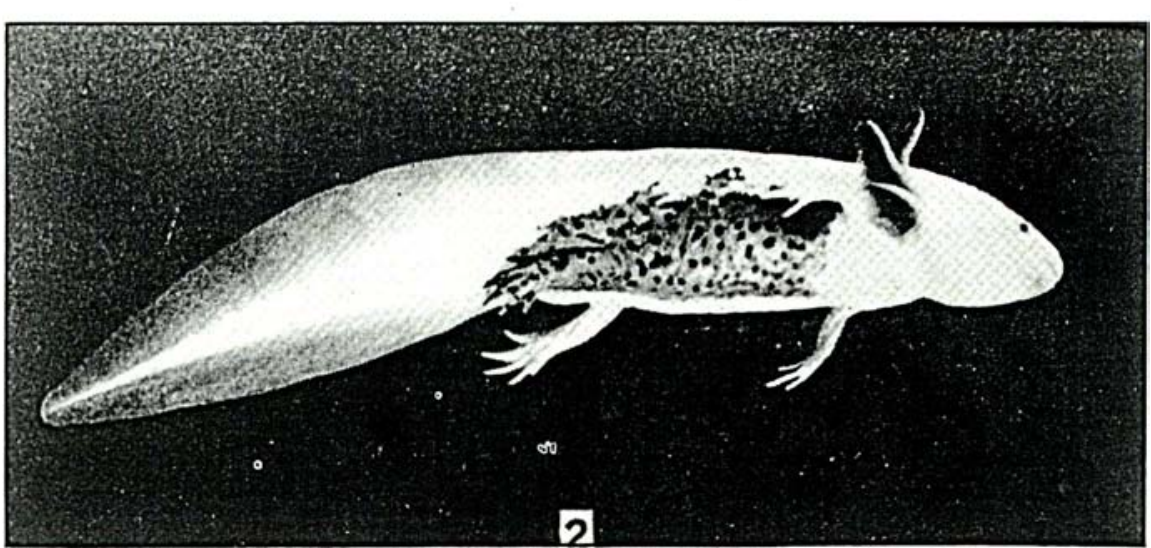

Figure 5. Un axolotl blanc qui a recu une greffe orthotopique d'un Ambystoma tigrinum pigmenté (selon le schéma de la figure 4). La gonade mâle qui a modifié l'ovaire est enlevée chirurgicalement avant la maturité sexuelle, que ce soit celle de l'hôte ou du greffon. (Emprunté à Humphrey [7].) 
férencicr et, chez les mâles, les ébauches encore minuscules de la prostate poursuivaient unc croissance normale (figure 6).

Carl Moorc abandonne donc la théorie hormonale de son maître et conclut, dans ses articles et dans un joli petit livre paru en 1947 [19], que les hormones n'ont rien à voir avec la différenciation du sexc, cclle-ci est contrôléc par des factcurs génétiques locaux, au niveau de chaque organc. La théorie hormonale de la différenciation du sexe était en crise.

Moi-mêmc, après avoir essayé vaincment de reproduirc l'effet freemartin chez le lapin, à l'aide de stéroïdes peu abortifs, je m'étais décidé à utiliser la méthode chirurgicale.

Pour obtenir des freemartins, il fallait unir en parabiose, avec échange des sangs, des fotus de lapin in utero. Mettre au point une méthode permettant cette chirurgic intra-utérine exigea de la patience. Lc résultat enfin obtenu en 1946 était déccvant : des fotus femclles unis en parabiose à des fœtus mâles ne montraient aucun "effet freemartin" en fin de gestation [20], unc constatation qui semblait corroborer les conclusions de Carl Moore, enfin connues en France.

Mais les résultats de la parabiose chez les batraciens étaient trop beaux ct trop convaincants pour qu'on pût ainsi renoncer à la théoric hormonale. Il valait la peinc de tenter de la vérifier chez les mammifères placcntaires. Pour ce faire, il était néccssaire de castrer des fotus de lapin in utero (figure 7, p. 268), af in de voir si les gonades jouent ou non un rôle dans la différenciation sexuellc.

L'entrcprise s'avéra rude. L'utérus acceptait mal d'être ouvert aux stades de la gestation qu'il était nécessaire d'explorer. Finalcment, en 1947, le résultat expérimental était clair bicn qu'inattendu : les fœtus des deux scxes, castrés au moment où lcur appareil génital était encore au stade indifférencié, sc développaient comme des femclles [21] (figure 8, p. 269).

Après contrc-épreuve, la conclusion s'imposait : le testicule, par scs sécrétions, impose le sexc masculin à l'apparcil génital contre une tendance féminine inhérentc, c'est-à-dirc que la féminisation survient que des ovai-

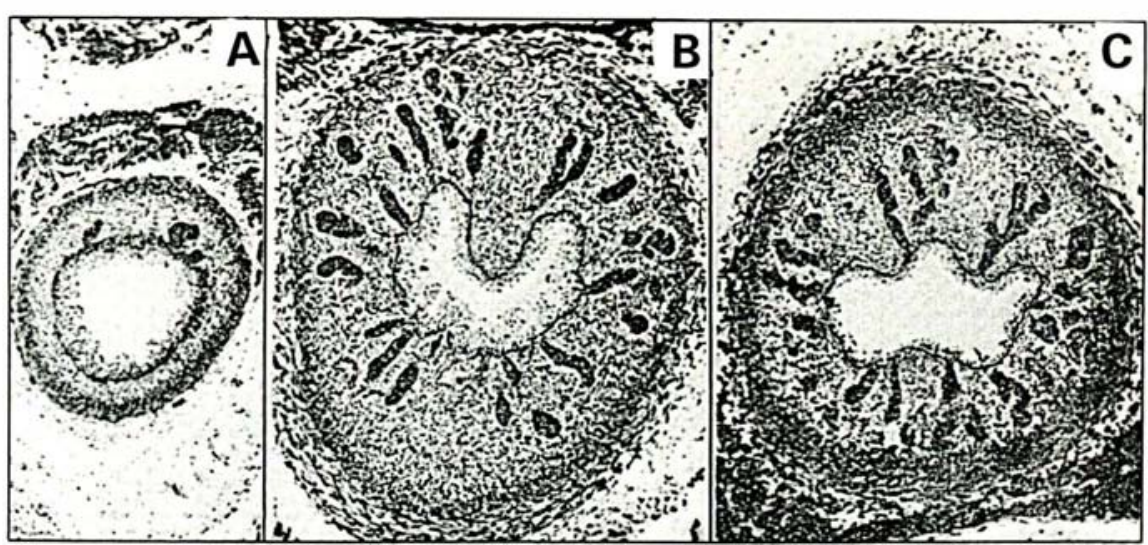

Figure 6. Coupes à travers la région prostatique de jeunes opossums étudiés pendant leur vie dans la poche marsupiale. (A) Prostate d'un mâle témoin de 20 jours. (B) Prostate d'un mâle de 52 jours castré à 20 jours. Malgré la castration, les bourgeons prostatiques se sont bien développés. (C) Prostate d'un mâle témoin de 52 jours. (Emprunté à C.R. Moore, Arch Anat Micro Morphol Exp 1950 ; 39 : 484-98.)

res soient présents ou non : il suffit qu'il n'y ait pas de testicule. Des données plaidant dans le même sens étaicnt pcu après apportées par Albert Raynaud, qui étudiait la souris [22].

Autrement dit, pour masculiniscr l'organismc, il faut quc, sous contrôle génétique, se différencient d'abord des testicules qui, à lcur tour, empêchent le reste du corps de devenir féminin.

Les testicules excrcent donc deux actions différentes: d'une part, ils stimulent le développement des canaux mâles et masculinisent les autres parties de l'appareil génital; d'autre part, ils font disparaître les canaux femelles, les canaux de Müller, c'est une sorte d'action antiféminine.

Or la testostérone, l'hormone testiculaire de l'adulte, lorsqu'elle est donnée au fotus mâle castré (figure 9, p. 270) ou à la femelle, est seulement masculinisante. Elle n'inhibe pas les canaux de Müller, comme le fait le testiculc chez le mâle, ou une greffe de testiculc sur lc fotus femelle (figure 10, p. 270). D'où l'intcrprétation, présentée en 1952, que lc testicule fotal produit probablement non seulement une hormone scmblable à cclle de l'adulte mais, en outre, unc secondc hormone, différente, inhibitrice des canaux de Müller [23]. L'expérimentation sur le fotus de lapin, expliquait aussi certains échecs antérieurs. Tout d'abord, chez lc lapin les sécrétions du testicule fœtal agissent localement et unilatéralcment, sans se répandre dans l'ensemble de la circulation, comme le montrait la greffe d'un testicule sur la femclle, ou l'ablation d'un seul testicule du mâle. D'où, probablement, l'insuccès de la parabiose réaliséc l'annéc précédente, en 1946, pour fairc des freemartins chez le lapin.

Par aillcurs, il s'avérait que la castration, si clle est un peu trop tardive, n'empêchait pas les organes mâles à peinc ébauchés de continucr à se dévclopper, l'impulsion initialc leur suffisait pour poursuivre leur mise cn place (figure 11, p. 271). Ainsi pouvaient se comprendre les résultats de Carl Moore.

Les expériences sur le fœtus de lapin avaient aussi un autre intérêt. Elles permettaient une interprétation simple du plus grand nombre des anomalies sexuelles humaines, pratiquement inexpliquées jusque-là : toute défaillance du testicule fœtal survenue au moment crucial laisse certaines structures se développer dans le sens féminin, spécialement les organes génitaux externes, anomalic la plus fréquente chcz l'homme. Le cas extrême serait l'absence complètc dc testicule chez des sujets génétiqucment masculins, et qui devraient alors se présenter comme des femmes $[24,25]$.

Or il existe des cas, heurcusement rares, de personnes se présentant comme des femmes totalcment 


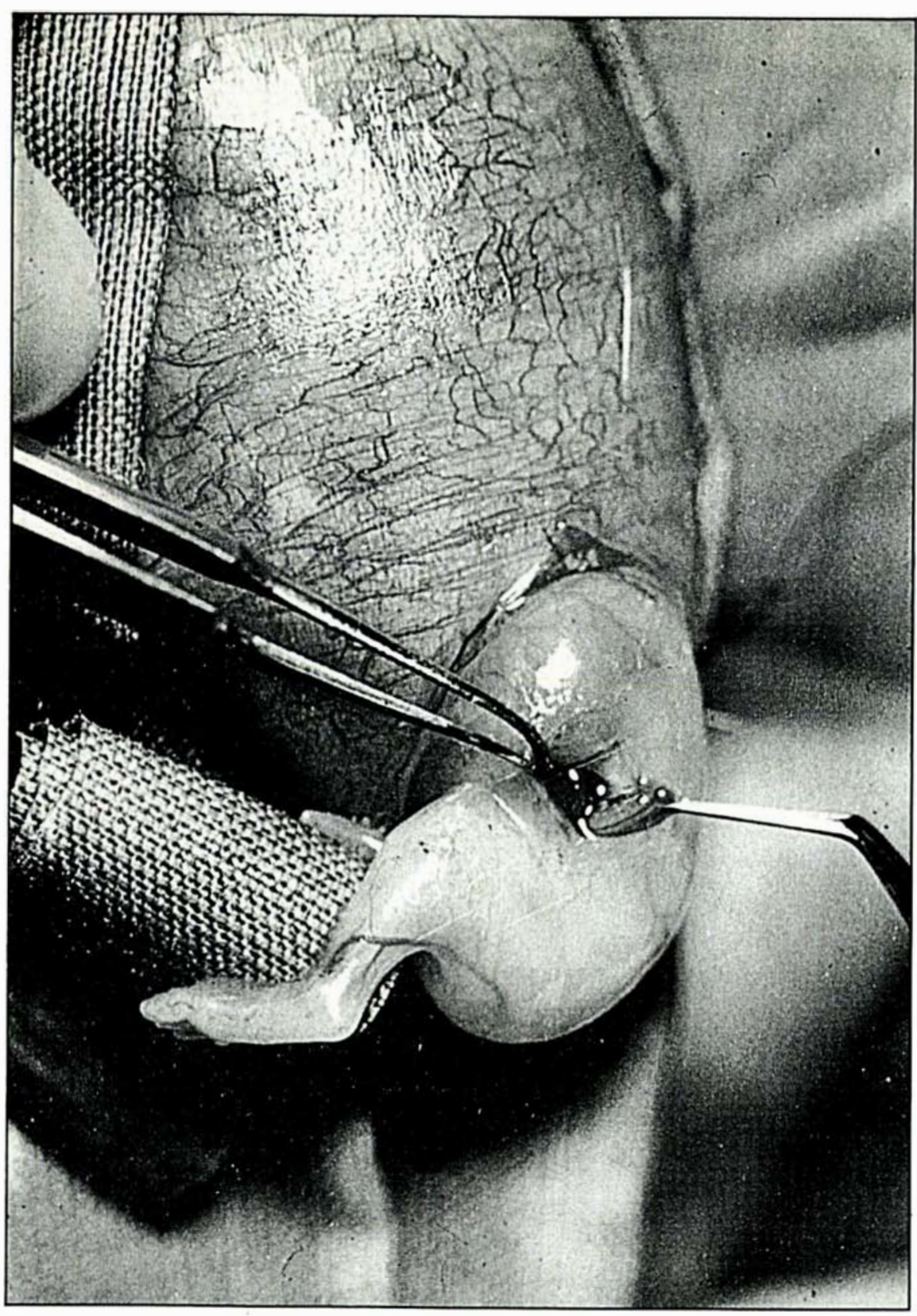

Figure 7. Castration d'un fotus de lapin de près de 23 jours. Une chambre utérine a été ouverte, la partie postérieure du fotus est extériorisée, son flanc est ouvert et le testicule, inséré sur le mésonéphros est exposé avant d'être réséqué. Après ablation bilatérale des testicules, le fœtus est replacé dans l'utérus jusque vers le terme. Pour des raisons de commodité, on a photographié l'opération sur un fœutus déjà trop âgé et trop grand pour donner des résultats figurant dans les figures 8 et 9 . dépourvues de glandes génitales. On pensait à l'époque qu'elles avaient souffert d'une agénésie ovarienne, c'cst-à-dire d'un défaut de formation des ovaires. Mais les fotus de lapin disaient qu'en fait il n'y a aucune raison d'invoquer une agénésic ovaricnne plutôt que testiculaire : toutes deux doivent être suivies d'unc différenciation féminine.

\section{L'insensibilité à la testostérone}

Ces interprétations furent présentées en 1949 à Mexico [25] puis à Baltimore. Là, elles reçurent un complément extrêmement important de la part de Lawson Wilkins, pédiatre et endocrinologiste à l'hôpital John Hopkins, à qui je rendais visite [26]. Wilkins étudiait, à cette époque, des femmes pourvucs de testicules mais dénuées de pilosité et qui ne répondaient pas à l'injection de testostérone (hairless women with testes).

En combinant les deux observations animale et humaine, Wilkins suggéra que ses patientes étaient en réalité des sujets génétiquement masculins, qui avaient différencié des testicules, mais qui étaient privés de la capacité de répondre à la testostérone dès la vic foetale ct par conséquent n'étaient pas masculinisés.

L'insensibilité à la testostérone fit ensuite l'objet de nombreuses investigations couronnées de magnifiques succès. On sait maintenant qu'elle relève de l'absence ou de l'anomalie des récepteurs cellulaires de la testostérone et qu'elle a les mêmes conséquences que l'absence ou l'insuffisance de la testostérone. On sait aussi que, dans certains organes, la testotérone doit être convertic en dihydrotestostérone (DHT) avant d'excrcer son action [27]. L'importance clinique de ce fait a été illustréc par Imperato McGinley et ses collaborateurs [28].

La physiologie, la pathologic et la chimie des réceptcurs des hormones sexuelles constituent à présent un brillant chapitre de l'endocrinologic.

\section{Les corpuscules de Barr et les chromosomes}

A la même époque, en 1949 toujours, au Canada, à London (Onta- 


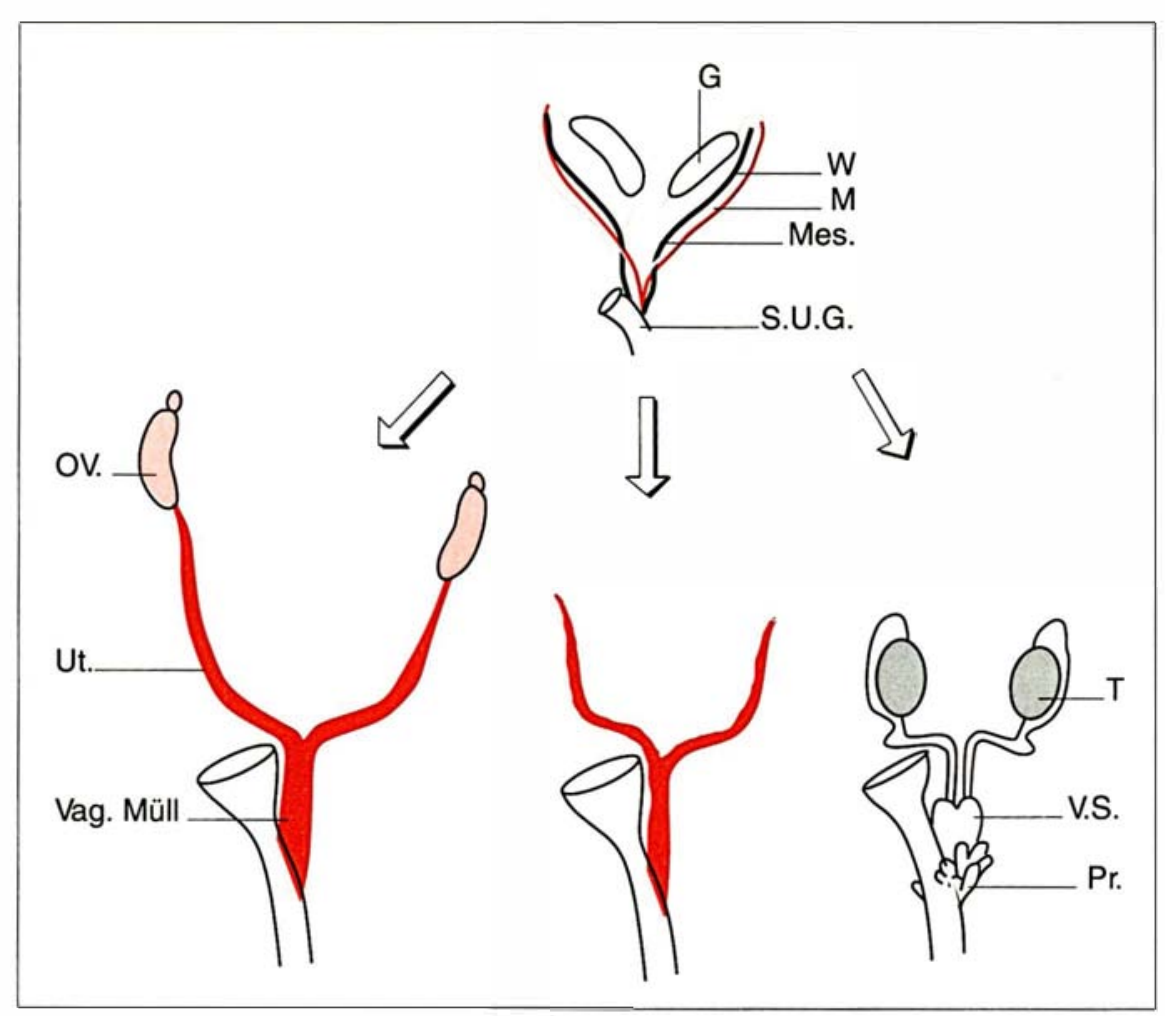

Figure 8. Présentation schématique de la différenciation sexuelle des voies génitales du fotus de lapin. A partir du stade indifférencié de 19 jours (en haut), caractérisé par la présence des canaux de Wolff (W) et des canaux de Müller (M) peuvent se différencier durant les 9 jours suivants soit les voies féminines (en bas à gauche), soit les voies mâles (en bas à droite), soit des voies de type féminin chez les castrats des deux sexes (en bas au milieu). $G$ : gonades ; $M$ : canaux de Müller ; Mes : mésonéphros; Vag. Müll : vagin müllérien ; Ov. : ovaire ; Pr. : prostate ; V.S. : vésicule séminale ; $T$ : testicule ; S.U.G. : sinus urogénital ; Ut: utérus; $W$ : canaux de Wolff. (D'après Jost, Mem Soc Endocrinol 1960; $7: 49-61.1$

rio), une équipe de chercheurs dirigée par Murray Barr travaillait, sous contrat avec la Royal Canadian Air Force, sur les effets de l'activité et du travail sur le système nerveux.

Ils étudiaient, au microscope, les cellules nerveuses de chats soumis ou non à des exercices. Divcrses modifications reproductibles étaient enregistrées. Mais, chez certains animaux et non chez d'autres, les noyaux des cellules de la moelle contenaient un petit granule de chromatine dont la présence ou l'absence étaient sans rclation avec l'expérimentation subie. Vérification faite, il s'avéra que ce corpuscule sc trouvait seulement dans les cellules des chattes et non dans $m / s n^{\circ} 3$, vol. 7 , mars 91 premier plan dans l'étude de la différenciation sexuelle, rôle qu'elles ne quitteront plus. Une vague de publications inonda le monde pendant près de dix ans sur ce sujet devenu facile, et les esprits s'accoutumaient à l'existence d'anomalies du sexe nucléaire ou chromosomique dans l'espèce humaine, notion nouvelle qui devait devenir si importante plus tard.

On constatait, par exemple, que les femmes privées congénitalement de gonades (agénésic gonadique) pouvaient avoir un "test de Barr" de type masculin ou féminin [31], conformément aux prédictions des fœtus de lapin [32].

Par ailleurs, certains sujets, d'aspect masculin et pourvus de testicules, possédaient des corpuscules de Barr dans leurs cellules (chromatine sexuelle "féminine") [33], alors que d'autres, d'aspect féminin et pourvus d'ovaires, avaient un test de Barr de type masculin [34]. On parla trop facilement d'inversion sexuclle. Cette interprétation s'avéra abusive lorsqu'on fut capable d'étudier les chromosomes humains.

Il est, en effet, curieux de constater qu'il fallut attendre 1956 pour que le nombre des chromosomes de l'espèce humaine fût connu, grâce à de nouvelles techniques d'obscrvation microscopique [35]. On identifia les 23 paires de chromosomes, en particulier les chromosomes $\mathrm{X}$ et $\mathrm{Y}$ [36]. L'année 1959 fut spécialement importante : on démontrait que, chez la souris [37] et chez l'homme [38], le sexe des gonades dépend directement de la présence ou de l'absence du chromosome $Y$, quel que puisse être le nombre des chromosomes $\mathrm{X}$, contrairement au mécanisme connu chez la drosophile. Ainsi, Jacobs et Strong [39], en Angleterre, étudiaient des hommes possédant des corpuscules de Barr et dont on aurait pu penser le sexe inversé : leurs cellules contenaient effectivement deux chromosomes X mais aussi un $Y$, ce sont des mâles XXY. Portant un chromosome $Y$, ces sujets avaient différencié des testicules et étaient masculinisés, malgré les deux chromosomes X.

Mais on montrait aussi que le chromosome $Y$ ne masculinise l'organisme que si des testicules se sont 


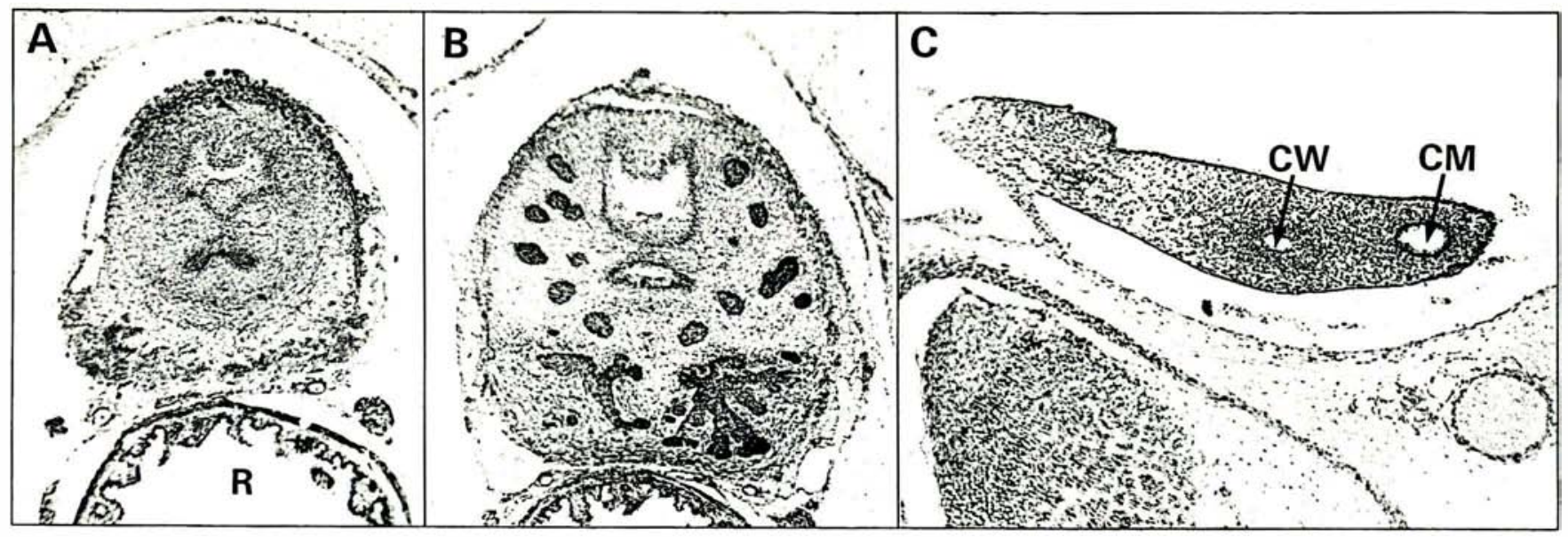

Figure 9. Action de la testostérone sur le fotus de lapin mâle castré. (A) Coupe de la région prostatique présomptive d'un fœtus castré à 19 jours 5 heures et sacrifié à 28 jours. On voit le sinus urogénital au niveau de l'abouchement des voies génitales. La prostate est complètement absente (R : rectum). (B) Même région d'un autre fœtus castré au même âge et qui a recu un implant de propionate de testostérone. La prostate, sous forme de bourgeons épithéliaux encore pleins, est plus avancée que celle d'un mâle normal de cet âge (28 jours). (C) Coupe des voies génitales du même fœtus que B: la testostérone a provoqué la persistance du canal de Wolff (CW) mais n'a pas inhibé le canal de Müller (CM), dans le méso génital. (Emprunté à Jost [21].)

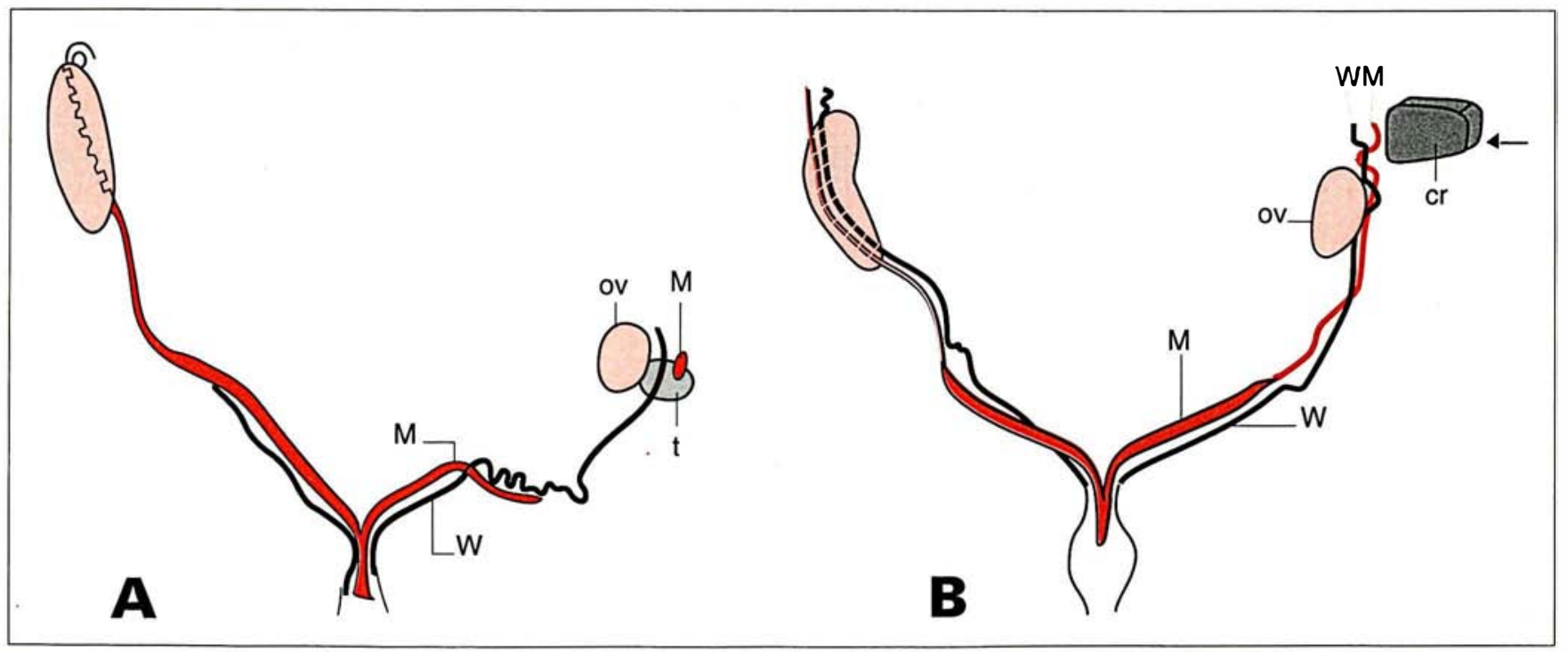

Figure 10. Action comparée du testicule fœtal et de la testostérone sur les voies génitales de fœtus femelles de lapin (reconstructions graphiques). (A) Cette femelle a reçu à l'âge de 20 jours une greffe de testicule fœetal (t) du même âge, insérée sur le mésosalpinx. A 28 jours, le canal de Müller (M) est partiellement inhibé à côté du greffon et le canal de Wolff (W, noir) plus largement maintenu. (ov : ovaire.) (B) Ce fotus a reçu au même âge un cristal de propionate de testostérone (cr) implanté à la même place que le testicule chez le fœetus $A$. Les canaux de Wolff (W) sont maintenus, mais il n'y a pas d'inhibition des canaux de Müller (M). (D'après A. Jost [21] (partie A) et III Réunion d’Endocrinologie de Langue française. Masson, 1955 (partie B).) 
développés et non en cas d'agénésie testiculairc [40].

Quant au test de la chromatine scxuelle, il continue à donner des indications cxactes lorsque la formule chromosomique est normale ; il permet, par excmple, de distinguer les fotus femelles des mâles, mais il est impuissant à expliciter les formules anormales.

\section{La dualité des hormones du testicule fotal}

Nouveau rebondissement tout différent en 1963, dont il faut indiquer l'origine. Certaincs substances synthétiques, dites progestatives parce qu'clles agissent comme l'hormone de gestation de l'ovaire, possèdent en outre le pouvoir détestable de masculiniser partiellement les fœtus féminins.

Ce fait, d'abord établi sur lc lapin [41], fut malheureuscment vérifié dans l'espèce humainc en 1958, année pendant laquelle on virilisa un grand nombre de pctites filles à travers le monde [42].

A la suite de cet accident prédit et qui aurait pu être évité, on exigea la démonstration sur l'animal de l'inocuité de ce type de drogue.

Or les cherchcurs des laboratoires Schering, de Berlin, avaient découvert unc nouvelle substance progestative très puissante, l'acétate de cyproteron, dont on devait naturellement éprouver l'action éventuelle sur les fœtus féminins. Friedmund Neumann et ses collaborateurs la donnent à des rates gestantes.

Le résultat fut surprenant. Non seulement les petites femelles n'étaient pas virilisécs, mais les mâles étaient féminisés [43] ! L'analyse de cette découvertc inattendue montra que la substance s'oppose à l'action de la testostérone, elle agit comme un anti-androgène.

Chez lc fotus, cet anti-androgène supprime l'action masculinisante du testicule fotal, mais non son action inhibitrice sur les conduits féminins, comme l'établit Walter Elger dans le même laboratoire, en 1966 [44].

Le testicule fotal produit donc bien deux hormones nécessaires à la différenciation du sexe, un androgène dont l'action est empêchéc par l'antiandrogène et une hormone inhibitricc
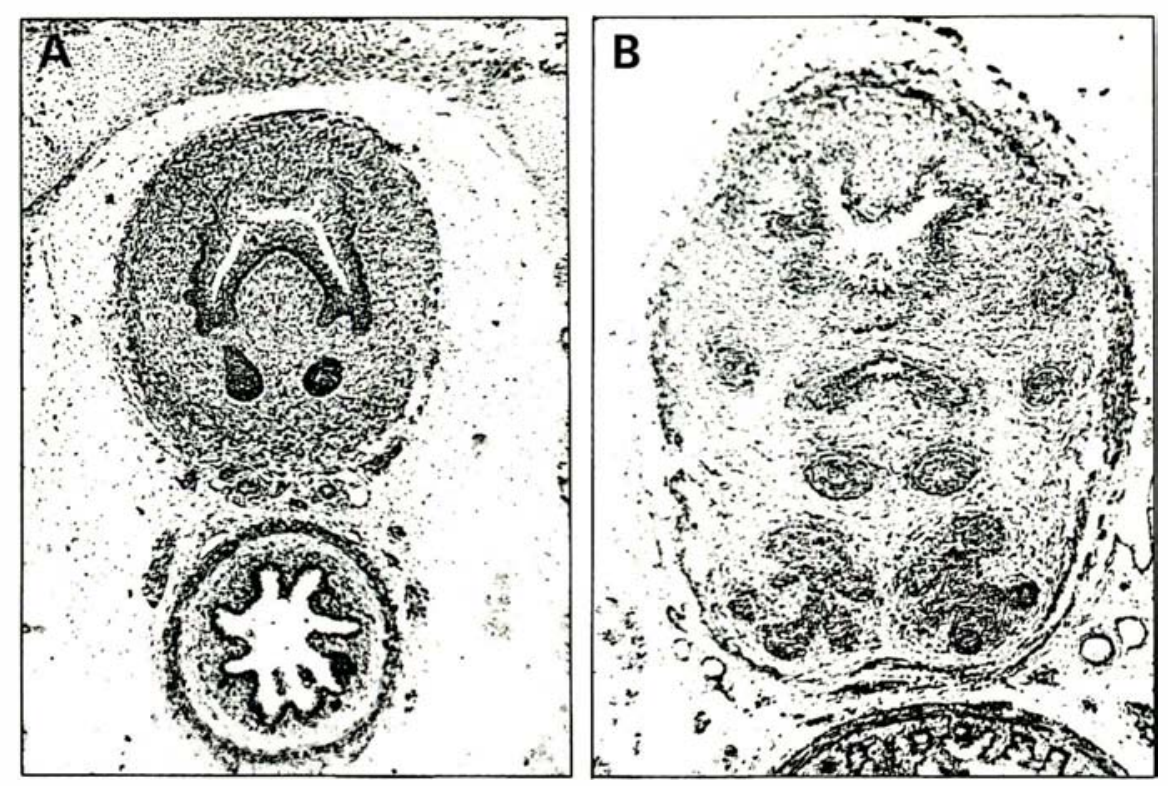

Figure 11. Développement de la région prostatique de fotus de lapin après une castration un peu trop tardive. (A) État de la prostate d'un fotus de 23 jours (deux bourgeons sont formés). (B) État à 28 jours de la prostate d'un autre fotus castré à l'âge de 23 jours. On a choisi le cas où la prostate s'est le mieux développée. (Emprunté à Jost [21].)

des canaux de Müller, indifférente, elle, à l'anti-androgène. La dualité de la sécrétion hormonale du testicule fœtal suggérée en 1952 [23], et qui avait trouvé un accucil plus favorable aux États-Unis qu'en France, se trouvait singulièrement confortée par les expériences allcmandes. Mais l'identification de l'hormone inhibitrice résistait aux tentatives.

C'est le mérite de Nathalie Josso, qui avait rencontré ce problème dans mon laboratoire, d'avoir isolé et purifié l'hormone inhibitrice en 1981 après dix ans de travaux fructueux récoltés avec une équipe de chercheurs enthousiastes [45].

Les succès du groupe parisien suscitèrent rapidement des émules aux États-Unis, spécialement une équipe bostonienne dirigée par Patricia Donahue. Les chercheurs d'une entreprise américaine de génie génétique, Biogen, appelés à la rescousse et sous la direction de Richard Cate, furent ainsi [46], de peu [47], les premiers, en 1986, à établir la structure du gène de l'hormone humaine et bovine et à pouvoir produire ces hormones. Une ère nouvelle s'ouvrait, cclle de l'analyse détaillée des propriétés de l'inhibiteur mülléricn.
Et voici que, tout récemment, Bernard Vigier et Solange Magre lui reconnaissent le pouvoir d'induire dans l'ovaire fotal des modifications ressemblant à celles des freemartins [48]. C'est le retour aux sources [49] !

Ainsi est-il donc désormais bien établi que la différenciation masculine est imposée à l'organisme par lc testicule grâce à la production de deux hormones - l'une masculinisante, l'autre antiféminine - et grâce à l'existence dans les ébauches sexuelles de récepteurs hormonaux appropriés.

Pour compléter l'histoire du développement de l'enfant mâle, il reste à expliquer pourquoi et comment se différencient les testicules.

\section{La différenciation testiculaire et l'interlude de l'antigène $\mathrm{HY}$}

Le mécanisme de la différenciation sexuelle de la gonade a, pendant plusieurs décennics, été expliqué sclon les conceptions qu'Emil Witschi avait dévcloppécs depuis 1931 [50].

Cclui-ci cnscignait que l'ébauche 
gonadique est faite de deux constituants antagonistes : le cortex, de signification féminine, et la médulla, de signification masculine, chacun produisant une substance inductrice appropriée (corticine et médullarine) (figure 12). Celui des deux inducteurs qui sort vainqueur de la compétition détermine le sexe final de la gonade. Les arguments invoqués en faveur de cette compétition n'étaient pas vraiment contraignants et, à partir de 1970, j'ai suggéré une interprétation plus simple : il suffit d'admettre que, comme le reste du corps, la gonade possède un programme inhérent féminin qui conduit à l'ovaire ; ce programme peut être contrecarré si un facteur, codé par le chromosome $\mathrm{Y}$, vient précocement imposer la différenciation testiculaire et empêche l'évolution ovarienne plus tardive [26, 51], (figure 13).

Il restait à identifier le facteur en question. En 1975, Stephen Wachtel, un ancien pilote de l'Air Force américaine reconverti dans l'immuno- logie, et Susumo Ohno, célèbre pour ses recherches sur le chromosome $\mathrm{X}$ et très porté aux concepts généraux, émettent l'hypothèse que ce facteur est l'antigène d'histo-compatibilité HY [52]. De quoi s'agit-il ? Il s'agit d'une protéine codée par un gène du chromosome $\mathrm{Y}$, et qui n'existe pas chez la femelle. Introduite dans l'organisme féminin, elle se comporte comme un antigène déclenchant une réaction immunitaire, ce qui explique le rejet des greffes de peau de souris mâle sur une femelle.

D'après Wachtel et Ohno, cette protéine si caractéristique du sexe masculin serait responsable de la différenciation du testicule chez les mammifères (et de l'ovaire chez les oiseaux, animaux chez lesquels c'est la femelle hétérogamétique $Z W$ qui porte l'équivalent $\mathrm{W}$ du chromosome $\mathrm{Y}$ ). Cette idée simple eut un succès prodigieux parmi les médecins et les biologistes. Elle provoqua pendant neuf ans un nombre immense de publications qui, d'ailleurs, allaient en se

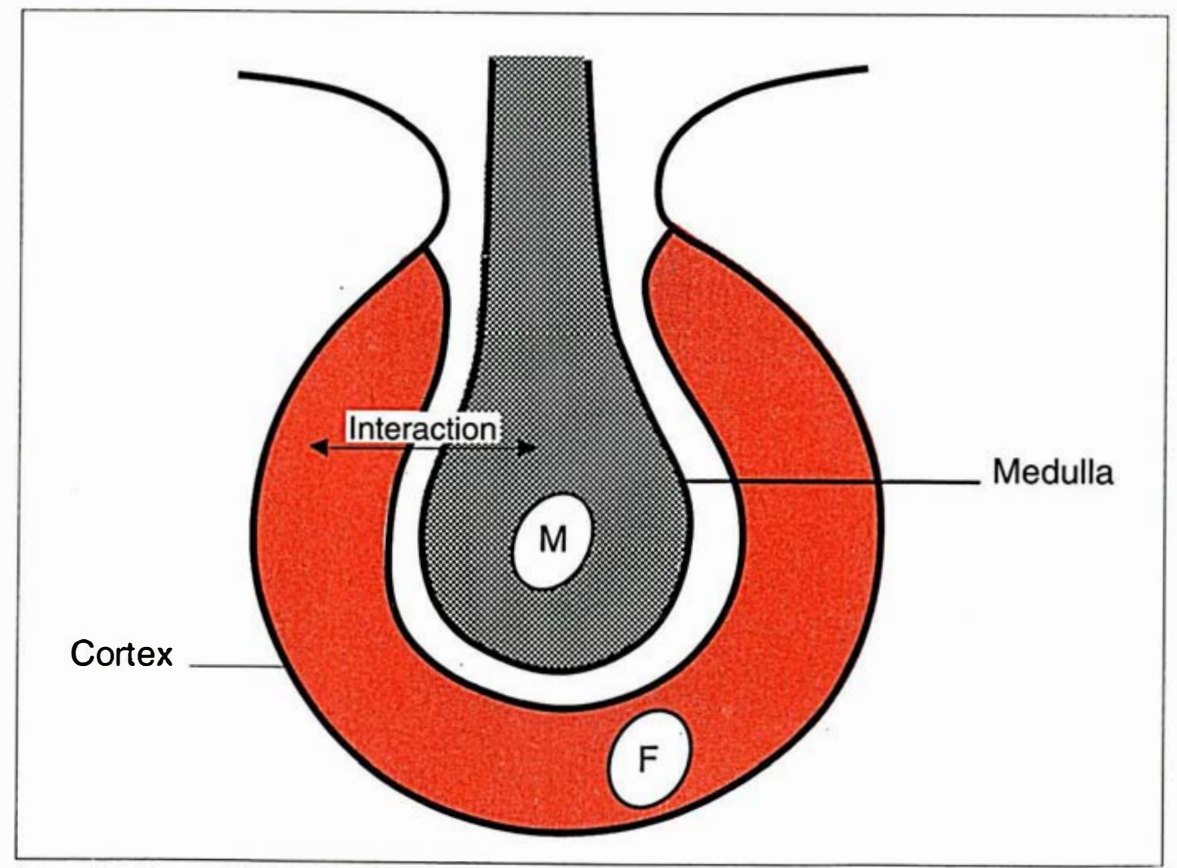

Figure 12. Interprétation par Witschi de la différenciation des gonades des vertébrés. Selon lui, celle-ci est constituée par deux composants, le cortex et la médulla, qui se développent respectivement sous l'influence des gènes de féminisation $(F)$ et de masculinisation (M), et qui sont en compétition au moyen de la sécrétion d'inducteurs antagonistes. (E. Witschi, J Fac Sci Hok- compliquant pour faire face aux contradictions, de plus en plus nombreuses, rencontrées. Les méthodes employées pour déceler l'antigène HY étaient, il est vrai, bien incertaines. Mais, pratiquement tous les articles ou livres traitant de la différenciation du sexe considéraient la théorie de l'HY comme vérité avérée. Cependant certains biologistes, peu nombreux, se rappelaient les données expérimentales antérieures inconciliables avec la théorie de l'HY et restaient circonspects [53].

En 1984, il fut démontré par Anne MacLaren et ses collaborateurs, en Angleterre, que, chez la souris, le gène codant pour l'antigène HY était distinct de celui qui détermine la différenciation testiculaire [54], ce qui fut confirmé par la suite (figure 14). L'interlude de l'antigène HY se termina rapidement, laissant cependant quelques déceptions par-ci, par-là.

\section{La quête du gène de différenciation testiculaire}

On passa alors à la quête du gène responsable de la différenciation testiculaire. Une fois encore, c'est l'étude de conditions anormales, rencontrées dans l'espèce humaine et chez la souris, qui fut à l'origine de progrès décisifs, aidée grandement par les avancées de la biologie moléculaire.

On sait depuis 1964 qu'il existe des hommes pourvus de deux chromosomes X, comme les femmes, et chez lesquels on ne décèle pas de chromosome Y [55]. On les appelle " hommes XX ".

En 1966, l'hypothèse avait été émise par Malcolm Ferguson-Smith, de Glasgow, qu'ils doivent posséder un fragment du chromosome $\mathrm{Y}$, contenant le gène de masculinisation, fixé sur l'un des chromosomes $\mathrm{X}$, ce que l'on appelle une translocation [56]. Cette hypothèse a été démontrée en 1984 par Jean Weissenbach, Marc Fellous et leurs collaborateurs, à l'Institut Pasteur, grâce à des sondes moléculaires [57].

Inversement, certaines femmes $\mathrm{XY}$ possèdent un chromosome $\mathrm{Y}$, mais ce chromosome a perdu un fragment contenant le gène de masculinisation, on parle de délétion. 


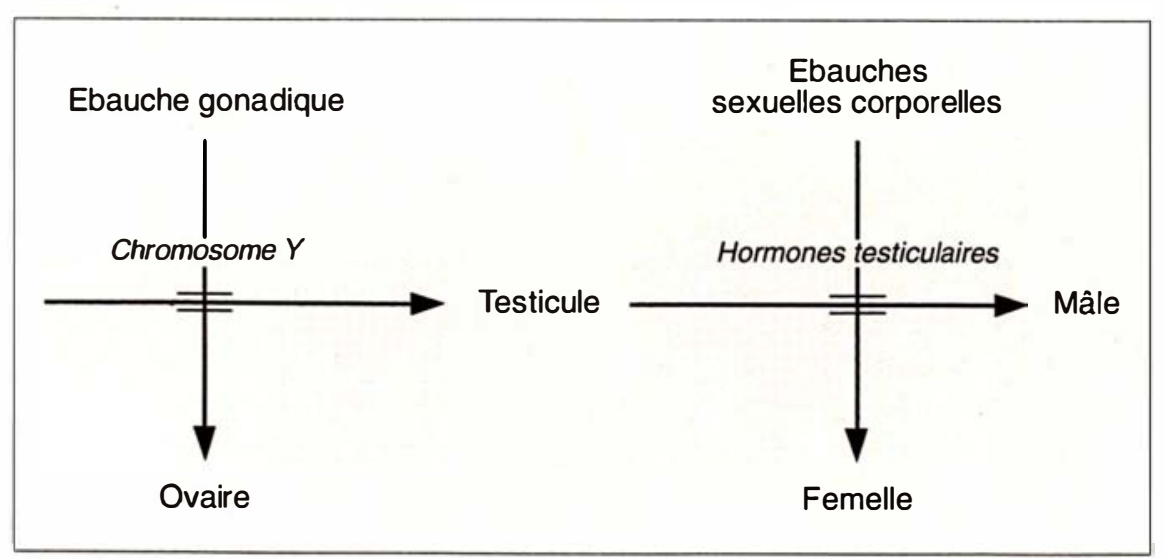

Figure 13. Schéma interprétatif de la différenciation sexuelle. Les gonades aussi bien que le sexe corporel deviennent féminins s'ils n'en sont pas empêchés par un mécanisme de masculinisation. (D'après A. Jost $(26,51]$.)

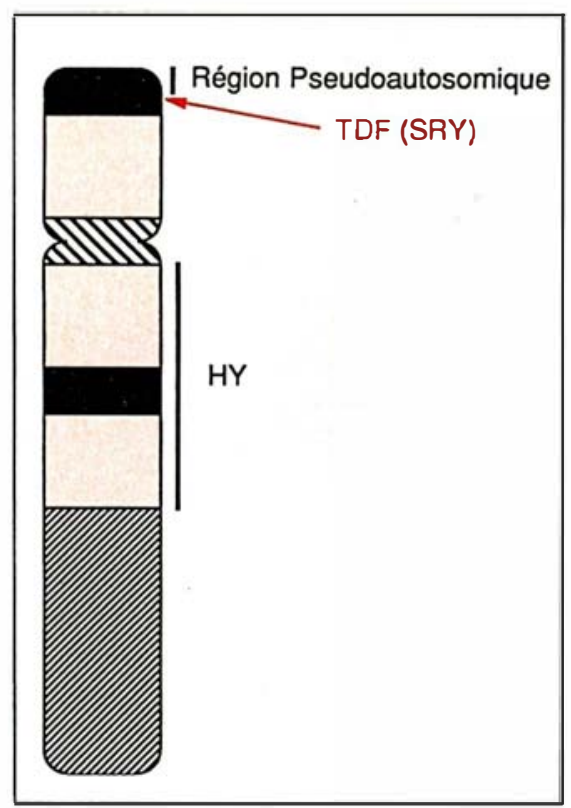

Figure 14. Représentation schématique du chromosome $Y$ humain. Les zones noires ou hachurées représentent des régions reconnaissables au microscope. L'étendue de la région pseudo-autosomique à l'extrémité du bras court du chromosome est indiquée par un trait vertical à côté du chromosome. La place du gène de détermination testiculaire ITDF ou SRYI est indiquée par une flèche. La région où se trouve le gène $\mathrm{HY}$ sur le bras long du chromosome $Y$ est indiquée par un trait vertical noir: la place de ce gène n'est pas encore exactement connue. (Schéma dù à l'obligeance de Jean Weissenbach.)
En étudiant le plus court fragment du chromosome Y transporté sur l'X chez les mâles $X X$, ou manquant à l'Y des femmes XY, on peut espérer identifier le gène de masculinisation. A la fin de 1987, David Page, de Cambridge, Massachusetts, et ses collaborateurs pensent avoir reconnu de cette manière la région du chromosome Y déterminant le sexe [58]. Le retentissement de cette publication a été considérable. Tous les journaux ont annoncé, en décembre 1987, la découverte du gène de masculinisation sous des titres variés dont certains se voulaient originaux. A Paris, l'un titrait "Le gène de la petite différence " [59], un autre "Madame sans gène " [60]. Ce dernier titre était particulièrement malheureux, puisque, selon le travail de Page, la séquence d'acides nucléiques concernée existait aussi chez la femme, ce qui d'ailleurs nécessitait des interprétations compliquées.

Cette difficulté, parmi d'autres, incitait les spécialistes à poursuivre l'enquête, et le succès du beau travail de Page fut éphémère [61].

Par suite du travail intense de plusieurs équipes, spécialement en Angleterre et en France, les découvertes se précipitent et l'analyse se précise. En décembre 1989, Palmer et ses collaborateurs étudient quatre autres sujets mâles XX [62]. Ils constatent que ces hommes sont dépourvus de la séquence spécifique du chromosome Y identifiée par Page et ses collaborateurs, mais qu'ils en possèdent une autre, située à côté de la région pseudoautosomale du chromosome Y (région de ce chromosome qui s'apparie avec l'X) (figure 14). Les caractéristiques de ce gène sont ensuite analysées chez l'homme [63] et la souris [64]. Enfin, en novembre 1990, Koopman et ses collaborateurs [65] mettent en évidence l'activité de ce gène, chez le fœtus de souris au moment même où vont se différencier les testicules, en identifiant l'ARN produit.

On peut donc prédire sans risque que l'identification exacte du gène est imminente. Une nouvelle étape sera alors franchie. Isoler un gène dont tout indique l'existence est certes réaliser une prouesse technique, mais c'est surtout ouvrir une nouvelle porte au parcours de la recherche car, le gène identifié, on pourra lui faire dire par quel moyen il déclenche la différenciation du testicule. On apprendra alors comment une séquence de quelques nucléotides parmi les trois milliards qu'en contient le génome humain amorce, comme d'une chiquenaude, la cascade d'événements prénatals qui font un mâle.

L'histoire que je vous ai contée n'est donc pas finie.

La longue série de recherches que je viens d'évoquer schématiquement a uni en une longue marche, parfois sinueuse, les talents et la curiosité d'un grand nombre de biologistes de formation diverse.

J'ai bien connu presque tous ceux dont j'ai cité les noms, à l'exception de trois des plus anciens, Lillie, Keller et Tandler.

Je sais que leurs travaux les plus originaux n'ont été planifiés par aucune autorité. Ils ont été guidés par la passion pour la recherche et le désir de comprendre de leurs auteurs, parfois aidés par l'imprévu. La liberté laissée à l'initiative des chercheurs a fait davantage pour le progrès de la science que n'aurait pu le faire quelque planification que ce soit. Cela aussi est leur message

Texte rédigé à partir d'un exposé fait durant la séance solennelle de l'Académie des sciences, le 26 novembre 1990. Le texte de cet exposé paraîtra également dans la Vie des sciences, série générale des comptes rendus de l'Académie des sciences. 


\section{Summary}

Twists and turns of rescarch : the study of sexual differentiation

The paper presents a glance through the history of a continuous series of research studies into the mechanisms of sex differentiation. Hormones were first implicated in the control of sexual differentiation in 1903, when Bouin and Ancel suggested that the internal secretion from the fetal testis imposed maleness on the fetus. The hormonal theory of sex differentiation became firmly established when Lillic (1916) gave a hormonal interpretation of the freemartin effect, in heterosexual twin pregnancies in cattle. This theory inspired research for several decades. Parabiosis between amphibian larvac introduced in 1925 , or exchange of the gonadal forming area between two larvac, permitted duplication of the freemartin condition and even the production of complete sex reversal and the obtaining of progeny from sex inversed females (Humphrey, 1945). In the mid thirties, the availability of steroid sex hormones raised great hopes as to the demonstration of the hormonal control of sex differentiation. Actually the effects of steroids were inconstant, sometimes unexpected and, in placental mammals, deceptive. In 1943, Carl Moore explored the part played by the testis in the sexual differentiation of opossums by castrating the young in the pouch. He was led to negate the role of hormones in sexual organogenesis and abandoned the theory of his master Lillic. On the contrary castration of the rabbit fetus in utero showed that the testis is the major organ in sexual differentiation (Jost, 1947). In its absence the whole genital tract becomes feminine whatever the genetic sex of the fetus, the presence or absence of ovaries being unessential. It was also suggested that the fetal testis could produce two kinds of hormones, an androgen and a factor responsible for the disappearence of the embryonic female ducts, a Müllerian inhibitor.

This concept met some resistance. Moreover the rabbit experiments permitted a new interpretation of human sex abnormalitics. Onc key issue being that in humans gonadal agenesis, whatever the genetic sex, should result in feminine features. These interpretations were complemented by Lawson Wilkins who suggested that some genetically male patients could be insensitive to androgens and therefore develop like females (with testes). The "sex chromatin " nuclear body discovered in 1949 was soon used extensively to assess the chromosomal or genetic sex of humans. It confirmed some of the interpretations derived from the rabbit experiments, but some of its shortcomings and failures appeared when after 1956, the human caryotype was recognized. In 1959 it was definitely cstablished that the $\mathrm{Y}$ chromosome is the bearer of the male sex determination. In 1963, in assays on the rat fetus a potent antiandrogen (cyproterone acetate), was discovered that inhibited the male ducts but not the female (Müllerian) ducts. This confirmed the early suggestion that the fetal testis produces two distinct hormones. Further studies conducted by Nathalie Josso led finally to the isolation in 1986 of the Müllerian inhibitor also called " anti Müllerian hormone " or "Müllerian inhibiting substance". The need for an explanation of the differentiation of the testis itself appeared as the necessary next step. A simplifying concept introduced by the writer in 1970 suggested that the gonad was programmed to become feminine unless some factor depending on the Y chromosome triggered maleness. In 1975, Wachtel, Ohno, et al. suggested that the product of HY histocompatibility gene was that factor. This view reigned for nine years, but this interlude came to an end when it was shown that the HY gene and the testis determining factor (TDF) were distinct.
Efforts were then made to identify directly the TDF, thanks to molccular biological methods applied to the chromosomes of $\mathrm{XX}$ males or of $\mathrm{XY}$ females. The first apparent success produced in December 1987 had to be revised in July 1989 and thereafter. The final identification of the gene is currently in progress. The new gene will then have to reveal how it triggers the cascade of events which result in a testis. The story summarized in the paper has not yet come to an end.

\section{RÉFÉRENCES}

1. Bouin P, Ancel P. Sur la signification de la glande interstitielle du testicule embryonnaire. CR Soc Biol 1903; 55 : 1632-4

2. Lillie Fr. The theory of the free-martin. Science $1916 ; 43 ; 611-3$.

3. Keller K, Tandler J. Über das Verhalten der Eihäute bei der Zwillingsträchtigkeit des Rindes. Untersuchungen über die Enstehungsursache der geschlechtlichen Unterentwicklung von weiblichen Zwillingskälbern, welche neben einem männlichen Kalbe zur Entwicklung gelangen. Wiener Tierarzll Monatschr 1916; 3 : 513-26.

4. Burns RK Jr. The sex of parabiotic twins in amphibia. $J$ Exp Zool $1925 ; 42$ : 31-89.

5. Humphrey RR. Studies on sex reversal in amblystoma. II. Sex differentiation and modification following orthotopic implantation of a gonadic primordium. J Exp Zool 1929 ; 53 : 179-219.

6. Burns RK. Role of hormones in the differenciation of sex, Chap. 2. In : Young WC, Corner GW, eds. Sex and Internal Secretions. Baltimore : Williams and Wilkins Co, 1961 : 76-158.

7. Humphrey RR. Sex determination in ambystomid salamanders : a study of the progeny of females experimentally converted into males. Am J Anat $1945 ; 76: 38-66$. 8. Dantchakoff V. Sur I'inversion expérimentale de l'ćbauche testiculaire chez l'embryon de poulet. CR Acad Sci (Paris) $1935 ; 200$ : 1983.

9. Wolff E, Ginglinger A. Sur la transformation de poulets mâles en intersexućs par injection d'hormone femelle (folliculine) aux embryons. Arch Anat Hist Embryol 1935 ; 20 : 219-78

10. Willier BH, Gallagher TF, Koch FC. Sex modification in the chick embryo resulting from in jections of male and female hormones. Proc Nall Acad Sci USA 1935; 21 : 625-31.

11. Dantchakoff V. Rćalisation du sexe à volonté par inductions hormonales. I. Inversion du sexe dans un embryon génćtiquement mâle. Bull Biol Fra Belg 1936; 70 : 241-307. 
12. Raynaud A. Modification expérimentale de la différenciation sexuelle des embryons de souris par action des hormones androgènes et astrogènes (ćtude des états d'intersexualité qui en résultent). Paris : Hermann et Cie, 1942 : 463

13. Padoa E. Effetto paradossale (mascolinizazione) sulla differenziazione sessuale $\mathrm{d}$ girini di Rana esculenta trattati con ormone follicolare. Monit Zool Ital 1936 ; 47 : 285-9. 14. Gallien L. Inversion expérimentale du sexe, sous l'action des hormones sexuelles, chez le triton Pleurodeles Waltlii Michach. Analyse des conséquences génétiques. Bull Biol Fra Belg 1954; 88 : 1-51.

15. Chang CY, Witschi E. Breeding of sexreversed males of Xenopus laevis Daudin. Proc Soc Exp Biol Med 1955; 89 : 150-2. 16. Jost A, Chodkiewicz M, Maulćon P Intersexualité du foetus de veau produite par les androgènes. Comparaison entre l'hormone fotale responsable du freemartinisme et l'hormone testiculaire de l'adulte. $C R$, Acad Sci (Paris) 1963 ; 256 : 274-6.

17. Moor CR. Modification of sexual development in the opossum by sex hormones Proc Soc Exp Biol Med 1939 ; 40 : 544-6.

18. Moore CR. Sexual differentiation in the opossum after early gonadectomy. $J$ Exp Zool 1943 ; 94 : 415-61.

19. Moore CR. Embryonic Sex Hormones and Sexual Differentiation. Springfield : Charles C. Thomas, $1947: 81$

20. Jost A. Sur la différenciation sexuelle de l'embryon de lapin. Expériences de parabiose. CR Soc Biol 1946 ; 140 : 463-4.

21. Jost A. Recherches sur la différenciation sexuelle de l'embryon de lapin. III

Rôle des gonades fotales dans la différencation sexuelle somatique. Arch Anat Micro Morphol Exp 1947; 36 : 271-315.

22. Raynaud A, Frilley M. Destruction des glandes génitales de l'embryon de souris, par une irradiation au moyen des rayons $\mathrm{X}$, à l'âge de 13 jours. Ann Endocrinol $1947 ; 8$ : 401-19.

23. Jost A. Problems of fetal endocrino$\operatorname{logy}:$ the gonadal and hypophyseal hormo nes. Rec Progr Hormone Res 1953; 8 : 379-418.

24. Jost A. Sur le rôle des gonades fotales dans la différenciation sexuelle somatique de l'embryon de lapin. CR Asoc Anat 1947 . $34: 255-63$

25. Jost A. Recherches sur le contrôle hormonal de l'organogenc̀se sexuelle du lapin et remarques sur certaines malformations de l'appareil génital humain. Gynécol Obstét 1950: $49: 44-60$

25 bis. Jost A. Investigaciones sobre el control hormonal de la organogenesis sexual de conejo y notas sobre ciertas malformaciones del aparato genital humano. Revista Mcdica Pasteur (Mexico) $1950 ; 23$ : 1-23 et Ginecolo gia y Obstetricia de Mexico 1952 ; 7 : 477-92. 26. Jost A. A new look at the mechanisms controlling sex differentiation in mammals (Fourth Lawson Wilkins Memorial Lecture) John Hopkins Med J 1972 ; 130 : 38-53. 27. Bruchovky N, Wilson JD. The conversion of testosterone to $5 \alpha$-androstan $-17 \beta$ ol- 3 one by rat prostate in vivo and in vitro. $J$ Biol Chem 1968 ; 243 : 2012-21.

28. Imperato-McGinley J, Guerrero L, Gautier T. Peterson RE. Steroid $5 \alpha$ reductase deficiency in man : an inherited form of male pseudohermaphroditism Science 1974; 186 : 1213.
29. Barr M, Bertam EG. A morphological distinction between neurones of the male and female, and the behaviour of the nucleolar satellite during accelerated nucleoprotein synthesis. Nature 1949 ; 163 : 676-7. 30. Moore KL, Graham MA, Barr ML. The detection of chromosomal sex in hermaphrodites from a skin biopsy. Surg Gynec Obstet 1953; 96 : 641-8.

31. Polani PE, Hunter WF, Lennox B. Chromosomal sex in Turner's syndrome with coarctation of the aorta. Lancel 1954 . $\mathrm{i}: 120-1$.

32. Grumbach MM, Van Wyk JJ, Wilkins L. Chromosomal sex in gonadal dysgenesis (ovarian agenesis): relationship to male pseudohermaphroditism and theories of human sex differentiation. J Clin Endocrinol Metab 1955 ; 15 : 1161-93.

33. Moore KL. Sex reversal in newborn babies. Lancel 1959 ; 1 : 217.

34. Hutchings JJ. Compete sex reversal : a case report. J Clin Endocrinal Metab 1959 ; 19 : 375-9.

35. Tjio JH, Levan A. The chromosome number in man. Hereditas 1956; $42: 1$.

36. Ford CE, Hamerton JL. The chromosomes of man. Nature 1956 ; 178 : 1020-3. 37. Welshons WJ, Russel LB. The Ychromosome as the bearer of male determining factors in the mouse. Proc Natl Acad Sci USA 1959 ; 45 : 560-6.

38. Ford CE, Polani PE, Briggs JH, Bishop PMF. A presumtpive XXY/XX mosaic. Nature 1959 ; 183 : 1030. 39. Jacobs PA, Strong JA. A case of human intersexuality having a possible XXY sex-determining mechanism. Nature $1959 ; 183$ : 302

40. Netter A, Lambert A, Lambruso R Trévoux R, Delzant F, de Grouchy J Lamy M. Dysgénćsie gonadique avec chromosomes XY. Premier cas. Bull $\mathrm{Mem}$ Soc Méd Hop Paris $1960 ; 70$ : 275

41. Courrier R, Jost A. Intersexualité fotale provoquée par la prégnéninolone au cours de la grossesse. CR Soc Biol 1942 ; 136 : 395-6.

42. Wilkins L, Jones HW, Holman GH, Stempfel RS. Masculinization of the female fotus associated with administration of oral and intramuscular progestins during gestation: non adrenal female pseudohermaphrodism. $J$ Clin Endocrinol Metab $1958 ; 18: 559-85$

43. Hamada $H$, Neumann F, Junkmann $\mathrm{K}$. Intrauterine antimaskuline Beeinflussung von Rattenfeten durch ein stark Gestagen wirksames Steroid. Acta Endocrinol 1963 $44: 380-8$

44. Elger W. Die Rolle der fetalen Androgene in der Sexualdifferenzierung des Kaninchens und ihre Abgrenzung gegen anderen hormonale und somatische Faktoren durch Anwendung eines starken Antiandrogens. Arch Anat Micro Morphol Exp 1966 ; $55: 657-743$.

45. Josso N, Picard JY, Vigier B. Purification de l'hormone antimüllérienne bovine à l'aide d'un anticorps monoclonal. CR Acad Sci (Paris) 1981 ; 293 Série III : 447-50. 46. Cate RL, Mataliano RJ, Hession C, Isolation of the bovine and human genes for Müllerian inhibiting substance and expression of the human gene in animal cells. Cell $1986 ; 45: 685-98$
47. Picard JY, Benarous R, Guerrier D, Josso N, Kahn A. Cloning and expression of cDNA for anti-Müllerian hormone. Proc Nall Acad Sci USA 1986 ; 83 : 5464-8.

48. Vigier B, Watrin F, Magre S, Tran D, Jusso N. Purified bovine AMH induces a characteristic freemartin effect in fetal rat prospective ovaries exposed to it in vitro. Development 1987 : 100 : 43-55

49. Jost A, Vigier B, Prépin J. Freemartin in cattle : the first steps of sexual organogenesis. I Reprod Ferl 1972 ; 29 : 349-79. 50. Witschi E. Génétique et physiologie de la différenciation du sexe. Arch Anat Micro Morphol Exp 1950; 39 : 215-40.

51. Jost A, Vigier B, Prépin J, Perchellet $J P$. Studies on sex differentiation in mammals. Rec Progr Hormone Res 1973 ; 29 : $1-41$.

52. Wachtel SS, Ohno S, Koo GC, Boyse EA. Possible role for $\mathrm{H}-\mathrm{Y}$ antigen in the primary determination of sex. Nature 1975 ; $257: 235-6$

53. Jost A. Basic sexual trends in the development of vertebrates. In : Sex, Hormones and Behaviour. Ciba Symposium 62. Amsterdam : Excerpta Medica, Elsevier, 1979 5-18.

54. MacLaren A, Simpson E, Tomonari K, Chandler Ph, Hogg H. Male sexual differentiation in mice lacking $\mathrm{H}-\mathrm{Y}$ antigen. Nature 1984 ; 312 : 552-5.

55. De la Chapelle A, Hortling H, Niemi M, Wennström J. XX sex chromosomes in a human male. First case. Acta Med Scand $1964 ; 412$ (suppl) : 25

56. Ferguson-Smith MA. X-Y chromosomal interchange in the aetiology of true hermaphroditism and the XXY. Klinefelter syndrome. Lancel 1966 ; ii : 475-6.

57. Guellaen G, Casanova M, Bishop C et al. Human XX males with $\mathrm{Y}$ single-copy DNA fragments. Nature $1984 ; 307$ : 172-3. 58. Page DC, Mosher R, Simpson EM, Fisher EM, Mardon G, Pollack J. McGillivray $B$, de la Chapelle $A$. The sexdetermining region of human $\mathrm{Y}$ chromosome encodes a finger protein. Cell 1987 51: 1091-104.

59. Nau JY. Le gène de la petite différence. Le Monde 6 janvier 1988 ; p. 15.

60. Ré C. Madame sans gène. L'Humanité 24 décembre 1987 ; p. 15

61. Weissenbach J, Petit Ch. Chromosome $\mathrm{Y}$ et détermination du sexe. médecine/sciences $1990 ; 6: 785-90$.

62. Palmer MS, Sinclair AH, Berta P, et al. Genetic evidence that ZFY is not the testis-determining factor. Nature $1989 ; 342$ : 937-9.

63. Sinclair $\mathrm{AH}$, Berta $\mathrm{Ph}$, Palmer MS, et al. A gene from the human sex determining region encodes a protein with homology to a conserved DNA binding motif. Nature 1990 ; 346 : 240-244

64. Gubbay J, Collignon J, Koopman P, et al. A gene mapping to the sexdetermining region of the mouse $\mathrm{Y}$ chromosome is a member of a novel family of embryonically expressed genes. Nature 1990 ; 346 : 245-250

65. Koopman P, Münsterberg A, Capel B, Vivian N, Lovell-Badge R. Expression of a candidate sex-determining gene during mouse testis differentiation. Nature 1990 ; $348: 450-2$. 